\title{
INFLUENCE OF GRAVEL AND ADJUVANT ON THE COMPRESSIVE STRENGTH AND WATER ABSORPTION OF CONCRETE
}

\author{
${ }^{1}$ Yahya FALL ${ }^{*}{ }^{2}$ Mimoun CHOURAK, ${ }^{3}$ Seif-Eddine CHERIF \\ ${ }^{4}$ Mahjoub HIMI, ${ }^{5}$ Mohammed ROUGUI \\ ${ }^{1}$ Applied Geosciences Laboratory, Faculty of Sciences, Mohammed I University \\ Oujda, Morocco, e-mail: y.fall@ump.ac.ma \\ ${ }^{2}$ National School of Applied Sciences, Oujda, Mohammed I University \\ Morocco, e-mail: mchourak00@gmail.com \\ ${ }^{3}$ Department of Civil Engineering, Faculty of Sciences and Technologies, Marrakesh \\ Morocco, e-mail: seif.cherif.00@gmail.com \\ ${ }^{4}$ National School of Applied Sciences, Al Hoceima, University Abdelmalek Essaidi \\ Morocco, e-mail: himi06@gmail.com \\ ${ }^{5}$ Laboratoire de Génie Civil et Environnement Ecole Supérieur de Technologie de Salé \\ Mohamed V University Rabat, Morocco, e-mail: rougui93@yahoo.fr
}

Received 3 May 2018; accepted 26 September 2018

\begin{abstract}
Concrete is the most commonly used material in civil engineering, given its economic cost and ease of manufacture. Its strength depends on the characteristics of its constituents. A good mix makes it possible to build solid, durable and economical structures. The present work aims to characterize the gravel of the Eastern region (quarry of eastern Morocco) by granulometric analysis and water absorption. Then, the studied gravel is used to produce three types of concrete (B20, B25 and B30), which were assessed in terms of water absorption and compressive strength. The last step is to study the effect of an adjuvant, more specifically a water reducer, on mechanical characteristics of local concrete. B25 concrete was chosen for the last step since it is the most used type in the region. Results show that adding a water reducer adjuvant, in this case 'Chrysoplast', can improve the compressive strength of concrete if the percentage added is accurately determined.
\end{abstract}

Keywords: Concrete, Compressive strength, Gravel, Water absorption, Chrysoplast

\section{Introduction}

Concrete is the most consumed manufactured material in the world, with around three tons per person each year. Its manufacture is justified by its low cost and availability of its components. However, with a view on sustainable development, a similar position in terms of manufacturing and consumption makes its impact on the

\footnotetext{
${ }^{*}$ Corresponding Author
} 
environment a major issue. The characterization of the concrete was the goal of many studies [1], [2], [3]. In order to contribute to the enhancement of concrete durability as well as the improvement of its performance, specifically in the region of eastern Morocco, the goal was set to use local materials and consider only the common means used for its manufacture.

The eastern region of Morocco is endowed with an important resource in building materials (gravel) and can play an important role in providing the region with its resources. Several tests on gravel were considered in order to determine its water absorption capacity, which can harm the durability of concrete. The main objective for the present study is to assess the variations on concrete characteristics by considering different combinations, varying the quantity and quality of its components.

Apart from its effectiveness on water absorption, 'Chrysoplast' plays an important role on the compressive strength of the concrete. Its chemistry, which uses the latest advances in molecule synthesis, provides: a wide range of dosage, workability and cohesion to the concrete.

\section{Water absorption of gravel}

Gravel is an important component in the manufacture of concrete; however some granular materials may have an internal porosity, which is detrimental to the water dosage of concrete, which affects its strength. Indeed, the determination of the water absorption coefficient makes it possible to evaluate the amount of water retained by the porosity of the gravel, in order to take into account the effective water dosage during the formulation of the concrete.

The water absorption coefficient is defined as the ratio of the mass increase of the sample caused by a partial water imbibition to the dry mass of the sample. This partial imbibition is obtained by immersing the sample in water for 24 hours at $20{ }^{\circ} \mathrm{C}$ at atmospheric pressure. The absorption coefficient $A b s$-is thus defined by:

$$
A b s=\frac{M a-M s}{M s} \cdot 100,
$$

where $M a$ is the mass in the air of the impregnated sample; $M s$ is the mass of the dried sample after washing on a $4 \mathrm{~mm}$ sieve and drying in an oven at $105{ }^{\circ} \mathrm{C}$.

\subsection{Materials}

To carry out this test, a sieve of $4 \mathrm{~mm}$ square mesh was used for the sieving the samples, which will be weighed with a precision balance of $0.1 \%$ of the test mass. A ventilated oven set at $105^{\circ} \mathrm{C} \pm 5^{\circ} \mathrm{C}$ was used for the drying of the samples, then the hydrostatic balance (container in which a wire mesh basket $\leq 3 \mathrm{~mm}$ is freely suspended) was used to weigh in water mass of the samples. Finally, an absorbent sponge of adequate size was used to wipe the samples. 


\subsection{Methodology}

The mass in the air of the soaked sample is determined as follows: after immersing the sample in water for 24 hours at $20{ }^{\circ} \mathrm{C}$ at atmospheric pressure, the sample is weighed and then carefully sponged with an absorbent cloth; the large elements are wiped individually. For the laboratory tests, after drying the materials in an oven at $105{ }^{\circ} \mathrm{C}$, the dry masses $M s$ were determined (Table I). The soaked masses $M a$ were weighed and found after 24 hours of immersion in water at $20^{\circ} \mathrm{C}$

\section{Table I}

Masses in soaked air and dry masses of samples

\begin{tabular}{|c|c|c|}
\hline Gravel & Ma (g) & Ms $(\mathrm{g})$ \\
\hline GII & 4499.8 & 4471.2 \\
GI & 2651.1 & 2633.8 \\
G0 & 1472.5 & 1459 \\
\hline
\end{tabular}

\section{Characterization of concrete based on our gravels GII, GI and G0}

\subsection{Protocol and materials}

The particle size analysis was carried out by dry method using a series of standard sieves $(0.063 \mathrm{~mm}, 0.125 \mathrm{~mm}, 0.25 \mathrm{~mm}, 0.50 \mathrm{~mm}, 1 \mathrm{~mm}, 2 \mathrm{~mm}, 4 \mathrm{~mm}, 8 \mathrm{~mm}, 16 \mathrm{~mm}$, $31.5 \mathrm{~mm}, 63 \mathrm{~mm}, 125 \mathrm{~mm})$. The material is subdivided into several granular classes of decreasing size. The masses of the different refusals and sieves are related to the initial mass of the material. The percentages thus obtained are evaluated in graphical form (Fig. 1)

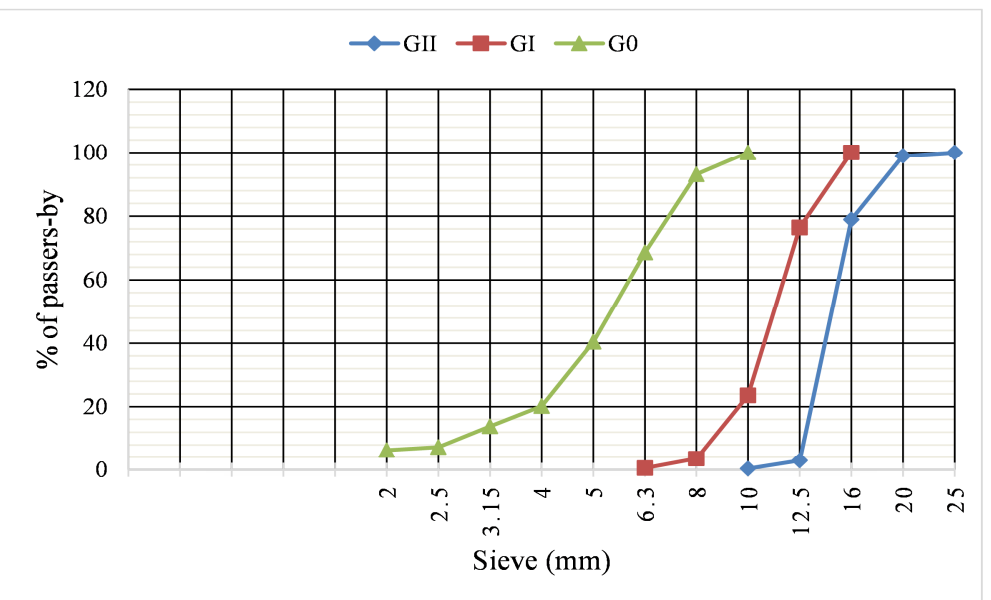

Fig. 1. Granulometric analysis of the three types of gravel 
Gravel has three granular classes $(D / d)$, where $D$ represents the maximum diameter of the grains and $d$ is the minimum diameter:

- GII gravel: $25 \mathrm{~mm} / 12.5 \mathrm{~mm}$ granular class;

- GI gravel: $16 \mathrm{~mm} / 6.3 \mathrm{~mm}$ granular class;

- G0 gravel: $8 \mathrm{~mm} / 2.5 \mathrm{~mm}$ granular class.

Generally, the refusal on the sieve $D$ is between $1 \%$ and $15 \%$, according to the formula: $D>1.56 d$. The refusal has been determined to be equal to: $\mathrm{GII}=0 \%, \mathrm{GI}=0 \%$, $\mathrm{G} 0=6.9 \%$.

A high percentage of coarse gravel has a negative impact on the concrete and can therefore impact its mechanical strength. The maximum size of the gravel $\left(D_{\max }\right)$ has an influence on the compressive strength of the concrete. The maximum increase of the overall diameter to a negative impact on the compressive strength also increases the risk of blockage, the reduction in the size of large gravel contribute significantly to the improvement of maneuverability [4], [5], [6].

The following equipment was used for granulometric analysis:

- Square mesh sieves in $\mathrm{mm}$;

- Balance, with an accuracy of $0.1 \%$ of the test sample mass;

- Ventilated oven set at $105^{\circ} \mathrm{C} \pm 5{ }^{\circ} \mathrm{C}$;

- Absorbent sponge of adequate size.

The cement used in this study is the CPJ45, which is manufactured in the Cement plant HOLCIM Oujda, delivered in $50 \mathrm{~kg}$ bags with a specific surface area of $3521 \mathrm{~cm}^{2} / \mathrm{g}$. According to Bug's empirical formulas, analyses give the following composition: $55.99 \% \mathrm{C}_{3} \mathrm{~S}, 14.26 \% \mathrm{C}_{2} \mathrm{~S}, 9.20 \% \mathrm{C}_{3} \mathrm{~A}$ and $7.23 \% \mathrm{C}_{4} \mathrm{AF}$.

The mixing water used during concrete formulation is that of the tap of the city of Oujda. Water used (drinking water from Oujda city: $\mathrm{Ph}=7.37$; alkalinity (or complete alkalimetric titre) $\mathrm{TAC}=11 \mathrm{meq} / \mathrm{l}$; conductivity $=1050 \mu \mathrm{s} / \mathrm{cm}$; total hardness $=42{ }^{\circ} \mathrm{F}$ ) in concrete production plays a vital role in the concrete mix, starting from governing the hydration process of cement, along with proper curing in order to reach the desired strength, not to mention managing workability and durability of the concrete structure [7].

\section{Dosage of the mixtures}

Three different mixtures were prepared in total, thus giving three types of concrete: B20, B25 and B30 (Table II). These mixtures containing each, a volumetric fraction of gravel (GII, GI and G0) with different water-cement ratios E/C (0.51, 0.57 and 0.64). The three types of concrete differ in the amount of cement, water and gravel. Note that concrete B30 is characterized by a larger amount of cement and B20 by the smaller amount. The concrete composition is:

\section{Mixing procedure}

The mixing procedure used for the concrete is in accordance with ASTM C192-06 [8].The life of concrete starts when the concrete components come into contact with water. Fresh concrete is a system of particles with empty spaces between them filled 
with water or air or a combination of both. The beginning point will then be taken as the point when water and cement come into contact with each other in the mixer [9].

Table II

Concrete composition

\begin{tabular}{|l|l|l|l|}
\hline Materials & B20 & B25 & B30 \\
\hline Volumetric fraction of gravels & $70 \%$ & $70 \%$ & $70 \%$ \\
Water/cement ratio (E / C) & 0.64 & 0.57 & 0.51 \\
Cement $(\mathrm{Kg})$ & 285 & 320 & 355 \\
Water $(\mathrm{L})$ & 185 & 184 & 182 \\
Gravel $(\mathrm{Kg})$ & 1392 & 1383 & 1375 \\
\hline
\end{tabular}

The whole was dried in an oven and cooled for 24 hours before mixing. The volume of water was corrected by Gravel Absorption. Water and cement were conditioned for 24 hours at room temperature before mixing.

\section{Chrysoplast}

The study was pursued using a water-reducing admixture in concrete whose properties are mentioned in Table III, to see its influence on the absorption and the mechanical resistance, especially the compressive strength. Super-plasticizers are added to cement pastes, mortars and concretes to increase their manoeuvrability at constant $\mathrm{E} / \mathrm{C}$ or to decrease their $\mathrm{E} / \mathrm{C}$ at constant fluidity. By increasing the dosage by superplasticizer, a saturation point is reached, which represents the quantity of superplasticizer beyond which there is no further measurable effect on the fluidity of the concrete. From this point on, any additional addition of super-plasticizer has only a very small effect on workability and therefore no longer has any effect on compressive strength [10].

Table III

Chrysoplast properties [11]

\begin{tabular}{|l|l|l|l|}
\hline Indicative information & Specifications \\
\hline Nature & Liquid & Density $\left(20^{\circ} \mathrm{C}\right)$ & $1.07 \pm 0.010$ \\
Color & Brown & Ph & $6.00 \pm 2.00$ \\
Lifetime & 12 months & Dry extract (SYNAD & $24.40 \% \pm 1.20 \%$ \\
& & IFFSTAR) & \\
& & Equivalent $\mathrm{Na}_{2} \mathrm{O}$ content & $\leq 2.00 \%$ \\
& & $\mathrm{Cl}^{-}$ion content & $\leq 0.10 \%$ \\
\hline
\end{tabular}

\subsection{Experimental method}

The mixtures were prepared in the laboratory. Three types of water-cement ratios $\mathrm{E} / \mathrm{C}$ were used, which are in some sort the three types of concrete (B30, B25 and B20). Their detailed proportions are given in Table II. Then at this standard dosage, a superplasticizer was added at $0.8 \%, 1 \%, 1.2 \%$ and $1.4 \%$ [11] of the total mass of each mixture, giving four distinct types of mixtures that is detailed later in this paper. With 
these different mixtures, tests of compressive strength were made as well as the evaluation of the water absorption. These tests occurred after having kept the different samples 24 hours after pouring in a storage chamber at 7, 14 and 28 days [12]. Indeed, the cure has the effect of advancing the hydration reactions that lead to clogging of the existing capillary pores. The extension of the cure time from zero to 28 days decreases by about half the initial absorption rate [13], [14].

\section{Compressive strength test}

Compressive strength tests were performed on compression testing machines (Fig. 1) using cylindrical samples.

The samples were stored for $24 \pm 4 \mathrm{~h}$ in water maintained at $20 \pm 5{ }^{\circ} \mathrm{C}$. The backing plates of the test machine must be cleaned. Center the specimen on the lower plate with an accuracy of $\pm 1 \%$ of the diameter for the cylindrical specimens. A constant loading speed in the range $0.2 \mathrm{MPa} / \mathrm{s}\left(0.02 \mathrm{~N} / \mathrm{mm}^{2}\right.$.s $)$ to $1.0 \mathrm{MPa} / \mathrm{s}\left(0.1 \mathrm{~N} / \mathrm{mm}^{2}\right.$.s $)$ was applied. Apply the load without shock and continuously increase it to the constant speed selected $\pm 10 \%$ until the test piece is broken [15].

\section{Water absorption test}

Difference in mass over a period of immersion gives an idea of the amount of water absorbed by the concrete due to capillary suction [16]. After 28 days immersion of the samples, their masses were determined. Then the samples were dried in an oven at $105 \pm 5{ }^{\circ} \mathrm{C}$ until the constant mass. So after obtaining the wet mass and the dry mass, water absorption was calculated using:

$$
\text { Water Absorption \% }=[(M H-M S) / M S] \cdot 100 \text {, }
$$

where $M H$ is the wet mass and $M S$ is the dry mass [17].

\section{Analysis and interpretation of the results}

\subsection{Gravel}

Using different sieves, the particle size analysis given in Fig. 1 helped to determine material composition precisely in order to deduce its mechanical characteristics [18]. It also helped to verify the development of the material in the quarry, by comparing its granulometric curve with the corresponding prescription. The information provided by the particle size analysis makes it possible to know in which types of tasks to use the analyzed materials. Among this information, the coefficient of flattening and the superficial cleanliness were exploited:

The coefficient of flattening noted A (in percentage) of gravel GII and GI obtained using granulometric analysis: this coefficient characterizes the shape of the gravel. It is a very important parameter because a bad form has an incidence on the handling and favors the segregation. The flatter the gravel the easier it is to place them in the concrete and the weaker they are because the existence of grains with pointed and flat edges 
create too much space. In the other case, the grain bonding can be potentially generated by zone, which creates the phenomenon of segregation. Once the concrete has been poured, the gravel migrates on one side and the cement paste also, which directly affects the mechanical performance of the concrete. It is therefore important to control the flattening coefficient.

The flattening of gravel plays a role in gravel-cement adhesion. In the case where a crack develops in the mass of concrete and meets a gravel element:

- If the gravel-cement adhesion is good, then the gravel stops the crack;

- If the adhesion is bad, the propagation is developed from the crack as if the gravel does not exist.

The superficial cleanliness noted $P$ (in percentage) of gravel (GII, GI and G0) [19] obtained using the particle size analysis: these impurities disrupt the hydration of the cement or cause defects of gravel-paste adhesion, which affects the strength of the concrete. Indeed, if the surface of the gravel is dirty, the adhesion with the hydrated crystals of the cement is bad. These impurities can be removed by washing the gravel. It is crucial that the gravel must be clean, where they must be devoid of any clay, earthy materials or dust from crushing. Gravel II: GII, $P=0.2 \%$; Gravel I: GI, $P=0.3 \%$; Gravel 0: G0, $P=3.8 \%$.

When formulating concrete, the dosage of the various elements used in concrete composition is done using the Dreux-Gorisse method. The granular proportions of the respective mixtures until one get a mixture that presents the best workability [20]. The technique makes it possible to add a correction of the mixing water of the concrete. This correction sometimes turns out to be zero. Knowing that this correction has already been made, the amount of water that should be added according to the type of concrete from gravel according to the absorption was also calculated.

The amount of water to be added does not depend on the size of the gravel, but depends on the amount of gravel used in the composition of the concrete (Table IV) and their absorption. This is explained by the fact that the smallest class, namely G0 $(2.5 / 8 \mathrm{~mm})$ requires a quantity of addition of water of $9.61 \mathrm{~L}$ more important than the class GI $(6.3 / 16 \mathrm{~mm})$ requesting a quantity of water of $7.53 \mathrm{~L}$.

\subsection{Concrete}

\section{Water absorption}

Increasing the temperature of the mixing water it results in increased hardened properties like compressive strength and water absorption at 3 days [21].

The water absorption of the concrete was corrected compared to the initial dosages with the Dreux-Gorisse method. This correction is due to the addition of water related to the absorption of water from gravel, since water absorption of uncorrected concrete is obtained by gravel dosing without taking into account the fact that concrete can absorb water that does not enter the starting mixing water. As a result, the corrected absorption is obtained taking into account the water absorbed by the gravel as indicated in Fig. 2. 
Table IV

Gravel absorption coefficients and quantities of water to be added

\begin{tabular}{|c|c|c|c|c|c|c|c|c|}
\hline \multirow{3}{*}{ Gravel } & \multicolumn{3}{|c|}{ Gravel $(\mathrm{Kg})$} & \multirow{3}{*}{$\begin{array}{c}\text { Absorption } \\
\text { Abs (\%) }\end{array}$} & \multirow{2}{*}{\multicolumn{3}{|c|}{$\begin{array}{l}\text { Water to be added based } \\
\text { on used gravel (L) }\end{array}$}} & \multirow{3}{*}{ Total } \\
\hline & \multirow{2}{*}{$\mathrm{B} 30$} & \multirow{2}{*}{ B25 } & \multirow{2}{*}{ B20 } & & & & & \\
\hline & & & & & B30 & B25 & B20 & \\
\hline $\begin{array}{l}\text { GII class } \\
12.5 / 25 \mathrm{~mm}\end{array}$ & 658 & 643 & 628 & 0.64 & 4.21 & 4.12 & 4.02 & $12.35 \mathrm{~L}$ \\
\hline $\begin{array}{l}\text { GI class } \\
6.3 / 16 \mathrm{~mm}\end{array}$ & 371 & 380 & 390 & 0.66 & 2.45 & 2.51 & 2.57 & $7.53 \mathrm{~L}$ \\
\hline $\begin{array}{l}\text { G0 class } \\
2.5 / 8 \mathrm{~mm}\end{array}$ & 346 & 360 & 374 & 0.89 & 3.08 & 3.20 & 3.33 & $9.61 \mathrm{~L}$ \\
\hline Total & $1375 \mathrm{~kg}$ & $1383 \mathrm{~kg}$ & $1392 \mathrm{~kg}$ & & $9.74 \mathrm{~L}$ & $9.83 \mathrm{~L}$ & $9.92 \mathrm{~L}$ & \\
\hline
\end{tabular}

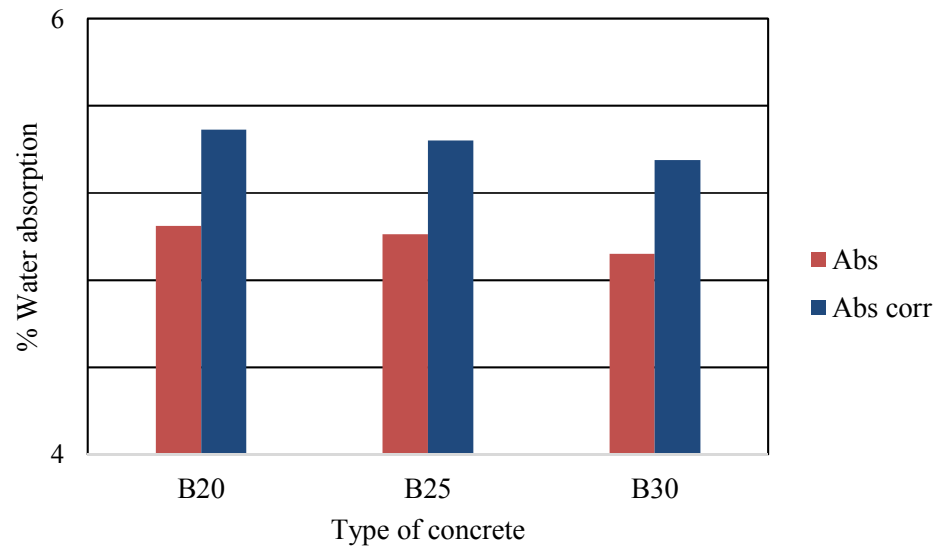

Fig. 2. Water absorption of concrete

\section{Characteristic compressive strength}

The characteristic compressive strength was evaluated for three types of concrete B20, B25 and B30 for periods of 7, 14 and 28 days as shown in Fig. 3. These types were made for different dosages mentioned in Table II. For a representation of the results at 7, 14 and 28 days, three samples were taken from each type (B20, B25 and B30). The average of the three values representing one of each type is shown in Fig. 3.

After evaluating the water absorption and the compressive strength of the three types of concrete (Fig. 2 and Fig. 3), B25 concrete was chosen for the rest of the study because it is the most used, most economical and on a profitability point of view, the most advantageous.

When the water-cement ratio is greater than 0.9 , the pore structure deteriorates rapidly and the compressive strength of the cementitious materials are affected by the porosity and the structure of the bubbles. Result shows that the porosity increases gradually with the increase of water-cement ratio [22]. 


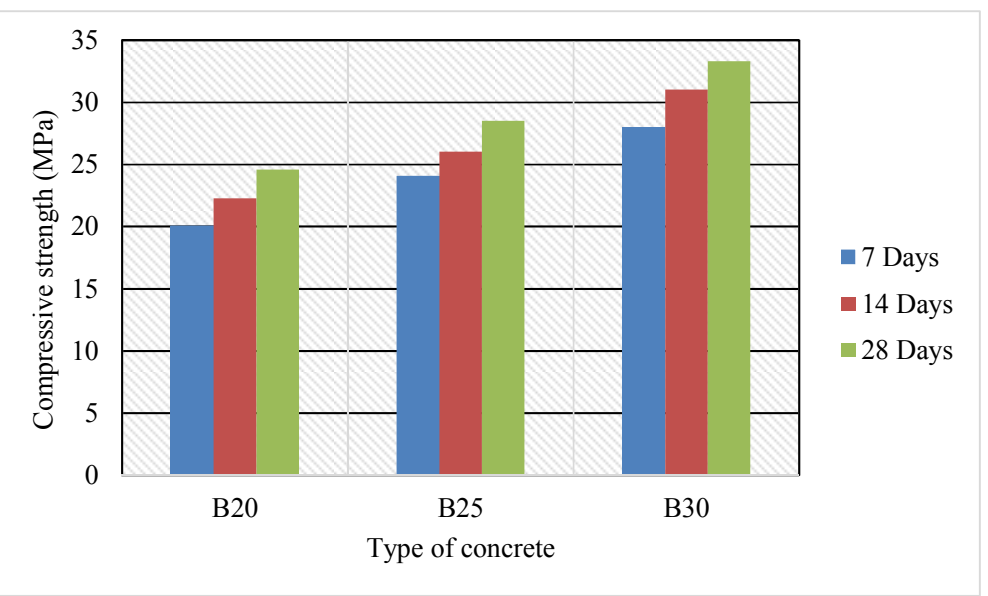

Fig. 3. Characteristic compressive strength of B20, B25 and B30 concrete

The E/C ratio has a very high influence on compressive strength, the lower the $\mathrm{E} / \mathrm{C}$, the lower the resistance the higher the resistance [13], [23], a reduction of 15 liters $\left(\right.$ per $\left.\mathrm{m}^{3}\right)$ in the quantity of mixing water leads to an increase of $5-10 \%$ in compressive strength [24].

Starting from the M0 case, various mixtures were tested in order to observe the effect of chrysoplast on compressive strength. Fig. 4 shows the mixtures: M1 and M2 record an increase of compressive strength at 7, 14 and 28 days. However, resistance increase stops at $1 \%$, because the M3 and M4 do not vary any more compared to the resistance of M2. These results are acceptable if we refer to the chrysoplast assay range: $0.3 \%$ to $1 \%$ [25]. This means that the maximum compressive strength of B25 is reached with a dosing of chryso at $1 \%, 1.2 \%$ and $1.4 \%$ corresponding to dosages M2, M3 and M4 (Table V).

Table V

Mixtures of concretes

\begin{tabular}{|c|c|}
\hline Concrete type & Description of concrete \\
\hline M0 & Standard (B25) \\
\hline M1 & Standard $+0,8 \%$ CHRYSO \\
\hline M2 & Standard $+1 \%$ CHRYSO \\
\hline M3 & Standard $+1,2 \%$ CHRYSO \\
\hline M4 & Standard $+1,4 \%$ CHRYSO \\
\hline
\end{tabular}

Absorption of the mixtures was also evaluated for the 28-day period (Fig. 5). This evaluation shows a decrease in the absorption of the standard M0 mixture following the addition of $0.8 \%$ and $1 \%$ of Chryso representing the mixtures M1 and M2 respectively. Beyond $1 \%$, the absorption resumes its increase for the mixtures M3 and M4 
respectively. Thus, beyond the mixture M2, Chrysoplast plays practically no longer its role of reducer and loses its influence on the water absorption of concrete (Fig. 5).

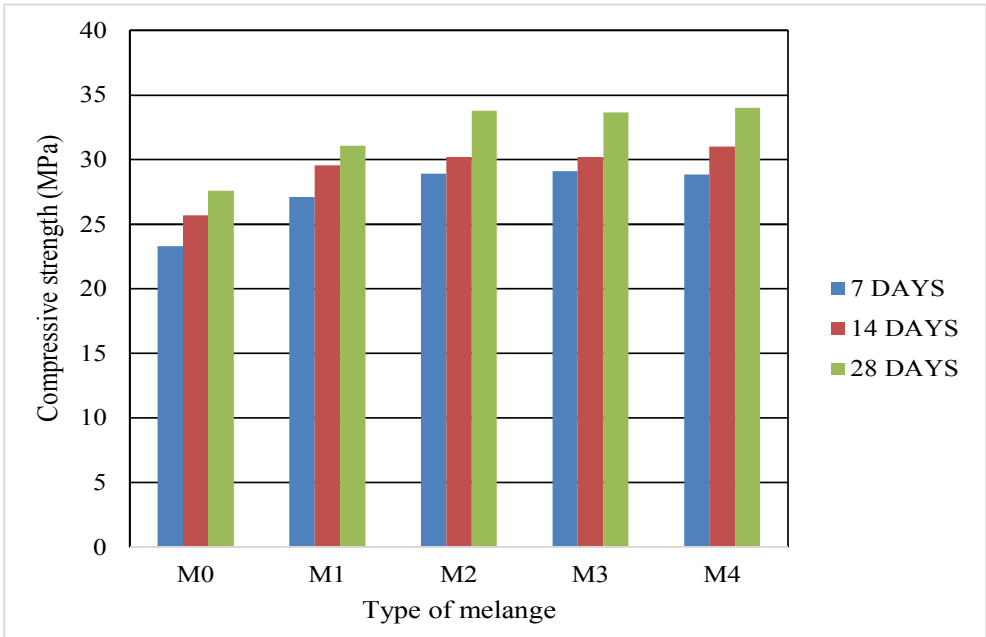

Fig. 4. Compressive strength of mixtures at 7, 14 and 28 days

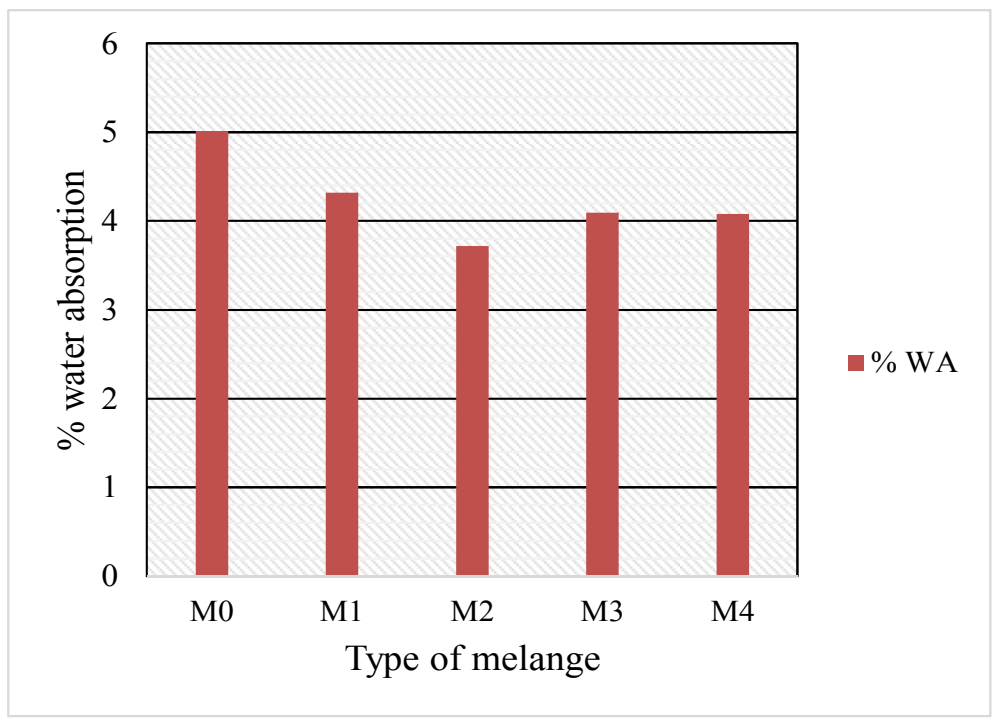

Fig. 5. Water absorption of 28-day mixture

When the water-cement ratio is greater than 0.9 , the pore structure deteriorates rapidly and the compressive strength of the cementitious materials are affected by the porosity and the structure of the bubbles. Result shows that the porosity increases gradually with the increase of water-cement ratio [22]. 
The $\mathrm{E} / \mathrm{C}$ ratio has a very high influence on compressive strength, the lower the $\mathrm{E} / \mathrm{C}$, the lower the resistance the higher the resistance [13], [23], a reduction of 15 liters (per $\mathrm{m}^{3}$ ) in the quantity of mixing water leads to an increase of $5-10 \%$ in compressive strength [24].

\section{Conclusion}

In this research, three types of gravel from the Oriental region of Morocco were studied. Gravel analysis includes the particle size assessment whose flattening coefficient and superficial cleanliness are deduced. The study also focused on the absorption of gravel and the contribution of corrected water addition. It was also a question of studying the compressive strength of three B20, B25 and B30 concretes designed with the gravel of this same study. Once these resistances were established, we chose B25 concrete for economic reasons to follow with the rest of the study. To B25 concrete, we applied an adjuvantation to improve its mechanical performance.

The results are divided into three phases: the first was the characterization of the gravels, which is related to the shape. The gravel GII with less flattened elements with a percentage of $12 \%$ while the gravel GI presenting more flattened elements of $14 \%$ flattening coefficient. In this same phase the superficial cleanliness was evaluated, with the gravel G0 being the cleanest with a percentage of $3.8 \%$.

The second phase of this study was to correct the water used in the composition of the concrete from the gravel. Water correction absorption of gravel has proved beneficial for the future, because with this correction, the concrete was dosed with the exact proportion which resulted in water additions of c $9.94 \mathrm{~L}, 9.83 \mathrm{~L}$ and $9.74 \mathrm{~L}$ to the B20, B25 and B30 concretes respectively.

The third and final phase of the study focused on the compressive strength of concrete and its improvement. Concrete B25 was the subject of this last phase. B25 improvement was reached thanks to the admixtures by chrysoplast, which increased the compressive strength of concrete B25 at 28 days of $5 \mathrm{MPa}$ for a percentage of $1 \%$ added.

\section{References}

[1] Junak J., Stevulova N., Ondova M. Concrete samples prepared with different types of wastes, Pollack Periodica, Vol. 9, Supplement 1, 2014, pp. 95-104.

[2] Ondova M., Stevulova N., Palascakova L., Estokova A. The study of concrete properties prepared with a proportion of fly ash, Pollack Periodica, Vol. 9, Supplement 1, 2014, pp. 105-115.

[3] Kidalova L., Stevulova N., Terpakova E. Influence of water absorption on the selected properties of hemp hurds composites, Pollack Periodica, Vol. 10, No. 1, 2015, pp. $123-132$.

[4] Bouhamou N., Belash H., Mesbah A., Mebrouki A., Yahia A. Influence of composition parameters on the behavior of fresh self-compacting concrete, Afr. Sci. Rev. Int. Sci. Technol, Vol. 4, 2008, pp. 1-20.

[5] Cordon W. A., Giilespie H. A. Variables in concrete aggregates and portland cement paste which influence the strength of concrete, ACI Mater. J. Vol. 60, 1963, pp. 1029-1052. 
[6] Yurugi M., Sakata N., Iwai M., Sakai G. Mix proportion for highly workable concrete, Proc. Int. Conf. on Concrete, Dundee, UK, 7-9 September 1993, pp. 579-589.

[7] Abdel-Magid T. I. M., Hamdan R. M., Abdelgader A. A. B., Omer M. E. A., Ahmed N. M. R. A. Effect of magnetized water on workability and compressive strength of concrete, Procedia Eng, Vol. 193, 2017, pp. 494-500.

[8] ASTM International Standard, ASTM C305, Practice for mechanical mixing of hydraulic cement pastes and mortars of plastic consistency, 2006, pp. 1-3.

[9] Souche J. C., Devillers P., Salgues M., Diaz E. G. Influence of recycled coarse aggregates permeability of fresh concrete, Cem. Concr. Compos, Vol. 83, 2017, pp. 394-404.

[10] Adjoudj M., Ezziane K., Kadri E. Formulation and property of a polycarboxylate adjuvant concrete, Communication Internationale Ecole Normale Supérieure d'Oran, Oran, 2013, pp. 1-9.

[11] Chrysoplast Omega 132, Water reducing plasticizing admixture, (in French) 2014, www.chryso.fr/p/5424/3/285/fr, (last visited 30 May 2018).

[12] French standardization P18-405, Concretes, Information test, Making and preserving specimens, (in French) Approved Standard, 01/12/1981.

[13] Rabehi M., Guettala S., Mezghiche B. Open porosity of embedding concrete: correlation between compressive strength and initial absorption, Eur. J. Envir. Civil Eng. Vol. 16, No. 6, 2012, pp. 730-743.

[14] Wirquin E., Hadjieva-Zaharieva R., Buyle-Bodin F. Use of concrete water absorption as a criterion for their durability, Application to recycled aggregates, Mater. Struct. Vol. 33, 2000, pp.403-408.

[15] French standardization EN 12390-3, Tests for hardened concrete, Part 3, Compressive strength of test pieces, (in French) 2003.

[16] Dhinakaran G., Chandana G. H. Compressive strength and durability of bamboo leaf ash concrete, Jordan J. Civ. Eng. Vol. 10, No. 3, 2016, pp. 279-289.

[17] French standardization EN 1916, annex F normative, Test method for the measurement of water absorption, (in French) 2003.

[18] French standardization P 18-560/P18-561, Sieve analysis by sieving, (in French) 1990.

[19] French standardization P18-591, Aggregates, Determination of superficial cleanliness, (in French) 1990.

[20] Lecomte A., de Larrard F., Mechling J. M. Predicting the compressive strength of concrete: the effect of bleeding, Mag. Concrete. Res, Vol. 57, No. 2, 2005, pp. 73-86.

[21] Naganathan S., Mustapha K. N. Effect of water temperature on concrete properties, Jordan J. Civ. Eng, Vol. 9, No. 3, 2015, pp. 292-302.

[22] Sang G., Zhu Y., Yang G., Zhuang H. Influence of water-cement ratio on property of lightweight cement based foam material, J. Mater. Sci. Eng, Vol. 33, No. 3, 2015, pp. 339-342.

[23] Gagné R., Aïtcin P. C. Superplasticizers for durable concrète, Proceedings of the International Conference on the Durability of Concrete, (in French) Monterrey, Mexico, 25 October 1993, pp. 200-217.

[24] Arnould M., Virlogeux M. Aggregates and light concretes, Review of ten years of research, Presses of the National School of Roads and Bridges, Paris, 1986.

[25] Chrysoft Omega 132, With CHRYSOPlast Omega 132, Fluidify your everyday concretes (in French) 2006, www.chryso.fr/p/5424/4/288/fr, (last visited 5 June 2018). 